\title{
TIME REFERENCE IN THE SERVICE OF SOCIAL ACTION
}

\begin{abstract}
The present study investigates the ways that members of society refer to time. Concrete methods for communicating about points in time and locating events in relation to them make relevant and thereby ground abstract time-reckoning in the lives of interactants. Through a taxonomy of references to time-termed "Absolute" and "Event-Relative", each with subcategories-, we describe the intrinsic affordances that different designs provide co-participants engaging in social interaction. In analyzing talk from both ordinary and institutional contexts, we demonstrate how these affordances can be mobilized in the co-construction and maintenance of intersubjectivity, in managing interpersonal relationships, and in conjunction with a variety of social actions. By describing how sociotemporal ordering is invoked, put into use, and contextually achieved in the immediacy of quotidian conduct, we posit that time-reckoning categories are social not only in their construction, but also in their everyday use.
\end{abstract}

\section{Keywords}

Time, Reference, Conversation Analysis, Ethnomethodology, Social Interaction 


\section{INTRODUCTION}

Time-reckoning — "the choice of temporal reference points and use of instruments to measure time" (Bergmann 1992:99) - has long been recognized as central to social life. Coordination of human activities requires shared methods for segmenting the flow of experience into temporal units, and locating events in relation to a common timeline (Adam 1995; Elias 1992; Flaherty 2011). As Durkheim (2008[1912]:10) observed:

[Time] is an abstract and impersonal frame which surrounds, not only our individual existence, but that of all humanity. It is like an endless chart, where all duration is spread out before the mind, and upon which all possible events can be located in relation to fixed and determined guidelines. It is not my time that is thus arranged; it is time in general, such as it is objectively thought of by everybody in a single civilization. That alone is enough to give us a hint that such an arrangement ought to be collective. And in reality, observation proves that these indispensable guidelines, in relation to which all things are temporally located, are taken from social life.

While a variety of disciplines have posited dichotomies in human perceptions of time-e.g., personal vs. scientific (Bergson 1971[1910]), inner vs. outer (Luckmann 1991), historical vs. experiential (Lyons 1977:688), subjective vs. objective (James 1922) - the more individual versus the more social orientations of time cannot exist in isolation from one another. Rather, members of a society must share some conception of temporality to be able to situate themselves and others in "the reality of everyday life" (Berger \& Luckmann 1967:28). "Without this," Sorokin (1943:173) remarks, "social life itself is impossible".

Temporal ordering and social structure-that is, time-reckoning and the social construction of time schedules - is a major theme in the contemporary sociology of time. Accordingly, much research on time-reckoning has focused on the social origin of basic temporal categories (Adam 1995; Durkheim 2008[1912]; Roy 2001; Zerubavel 1985). For instance, Zerubavel notes that unlike the year and the month, the institution of the week has no basis in the natural world and is entirely a matter of social convention, including as few as 2 days or as many as 20, cross-culturally (1985:55,75; cf. Sorokin \& Merton 1937:624-625). Because temporal 
categories of this kind are not universal, the cultural resources used to parse a timeline are part of what defines and constitutes membership in a given society (Durkheim 2008[1912]; Roy 2001).

Various social theorists have incorporated temporal ordering as an essential component in the accomplishment of social action. Mead (1932, 1936), for example, emphasized how the meaning of the present shapes interpretations of the past and future (see Flaherty \& Fine 2001). Temporal sequencing and coordination were likewise essential for Schütz (1962), who underscored the crucial role that timing plays in how social actors work to achieve intersubjectivity. It was the ethnomethodological work of Garfinkel (1967) which then took temporality out of the individual actor's head, making it a public and accountable feature of collaboratively constructed interaction. As Garfinkel demonstrated, "if we disregard [the] temporally constituted character [of understandings] and treat them instead as precoded entries on a memory drum," we are unable to explain how it is that participants are able to understand "what they are really talking about" (41). The achievement of intersubjectivity and the constitution of action must therefore be conceptualized as a temporally emergent, collaborative, and publically accountable process between interactants.

Given this background, let us reconsider the definition of time-reckoning with which we began: "the choice of temporal reference points and use of instruments to measure time" (Bergmann 1992:99). From this we can now ask: What exactly are "temporal reference points"? How do social actors "use" them? And how are these "choices" implicated in the collaborative production and recognition of social action in everyday life? If time is, to quote Luckmann (1991:151), "the condition of sociality that is achieved again and again in the continuously incarnated contemporaneity of face-to-face-interaction," what does that face-to-face interaction entail? 
In the present study, we contribute to this social constructivist perspective on time by investigating how language provides mechanisms through which situating time can be accomplished. Our analysis thus entails a departure from previous research on the existence of temporal categories and sociotemporal ordering as objects of investigation, to their actual usage in situated interaction. We show that different ways of referencing time — of making 'cuts' on the timeline-constitute the concrete practices through which moments in time are formulated, communicated publically, and mobilized for the purposes of social action. Specific linguistic methods for communicating about points on the timeline and locating events in relation to them make relevant and thereby ground abstract time-reckoning in the lives of interactants. We argue that making references to time in the immediacy of quotidian conduct thus lies at the core of the interface between time-reckoning and action, rendering time a social phenomenon not only in its construction, but also in its everyday use.

\section{REFERENCE IN INTERACTION}

Referring expressions are formulations that a speaker uses to bring about mutual orientation to a "person, place, object, time or other ontological category" (Enfield 2013:433).

Intrinsic to the production of a reference form is what Mead (1934) called "taking the role of the other". In order to engage in coordinated action and establish joint understanding, speakers must distinguish what they know from what their hearers know about the world, and take that into consideration in designing their references (Clark 1996; Garfinkel 1967; Goffman 1983a, 1983b; Grice 1957; Mead 1934; Schütz 1962; Tomasello 2008). Psychologists have termed this ability, which first emerges when a child is aged 3-4, theory of mind (ToM) (Astington 2006). As Heritage (2013:370) observes: "Without recognizing the nature and content of knowledge held by others and distinguishing it from our own, it would be impossible to refer 
to persons, places and things using reference forms that will allow others to recognize who (or what) is being talked about" (Enfield \& Stivers 2007; Sacks \& Schegloff 1979).

Sheer recognizability is not the only consideration for speakers in making a reference. In the case of referring to persons, for example, researchers have observed that languages provide speakers with many more options than are needed to refer to a single individual. The same person might be referred to as 'Adam', 'Dr. Smith', 'my friend', 'your brother', or 'the really tall guy', in the same way as one might describe where Adam is standing using space references such as 'right in front of me', 'to the left of the house', 'in the yard', 'in my neighborhood', or 'in Los Angeles' (see Enfield 2013 for an overview). Given this array of possible and equally 'correct' reference formulations, the fact that a speaker selects this option, for this hearer, at this moment accomplishes crucial interpersonal and action-relevant work for the co-participants. This practice, known as recipient design (Sacks, Schegloff \& Jefferson 1974), builds on Goffman's (1967) notion of face work. Participants in social interaction constantly and unavoidably take what Goffman calls a line: "A pattern of verbal and nonverbal acts by which [a participant] expresses his view of the situation and though this his evaluation of the participants" (5). Use of a particular reference form over another is one concrete means through which speakers can take a line.

While the sociology and anthropology of time have received much attention from a variety of perspectives (e.g., Adam 1995; Durkheim 1951[1897]; Flaherty 1999, 2011; Geertz 1973; Gell 1992; Giddens 1991; Postill 2002; Roth 1963; Roy 2001; Urry 1985; Zerubavel 1981, 1982, 1985), relatively few authors have examined how time is referenced in naturalistic talk-ininteraction (Button 1987; Enfield 2013; Sacks 1988/89; Schegloff 1972). We define time references, or $T R s$, as the repertoire of social and linguistic resources available to members of a 
given society to indicate particular points on the timeline. ${ }^{1}$ Making references to time, we argue, is a primary means through which social actors are able to "temporally punctuat[e] the stream of experience"-and in particular ways - at the ground level of moment-by-moment interaction, which Garfinkel (1967:274) maintains is essential to the collaborative "gearing" of action and understanding.

Consider example (1), taken from a medical visit. Here, the patient produces two distinct time reference formulations of what is ostensibly 'the same' temporal reality, in response to the doctor's inquiry.

(1) Mishler $(1984: 165)^{2}$

01 DOC: How long have you been drinking that heavily?

02 PAT: Since I've been married

03 DOC: How long is that?

04 PAT: ((giggle)) Four years

This example clearly illustrates how the same point in time can be referred to in a variety of ways. In addition to these two formulations (lines 2 and 4), the patient could have located the onset of her drinking with 'since the late seventies', 'since the Carter administration', 'after I got my hip replaced', 'for a few years', 'for 200 weeks', 'since June $7^{\text {th }}$ of 1978 ', and so on. While each of these other options may be equally 'correct' in that each demarcates roughly the same point in time, she did not select any of these alternatives. ${ }^{3}$

This, then, becomes our puzzle: What does this patient convey to her doctor with these specific time reference designs? Put more generally, what enabling affordances-defined by

\footnotetext{
${ }^{1}$ This definition does not include tense morphology, which while indicating past/present/future, does not reference a particular moment in and of itself: 'I went to the store' invokes a prior time, but it does not include an explicit time reference (cf. 'I went to the store yesterday'). The framing of this definition is also motivated by crosslinguistic research which reports that "most languages have little or no specialized grammatical apparatus (beyond a limited number of tense distinctions) for indicating deictic time, and thus the bulk of such reference is due to the properties of particular lexical items" (Anderson \& Keenan 1985:300).

${ }^{2}$ For transcript conventions, see Jefferson (2004).

${ }^{3}$ The contextual and sequential aspects of this example will be discussed in greater detail in a later section, as example (12).
} 
Gibson (1979) as "action possibilities" — do distinct time references offer their speakers? What does an interactant accomplish by mobilizing one reference form over another?

Answering these questions requires the use of terminology that categorically distinguishes different ways of referring to time; thus our first step is to systematically organize time reference formulations into a taxonomy. This will provide us with the language necessary to then examine the social and interactional work achieved by mobilizing particular TR designs in ongoing courses of action.

\section{DATA AND METHODS}

Data for the present analysis are culled from a corpus of time references in both everyday and institutional talk, including a variety of speakers and contexts. Everyday interaction refers to friends and family members conversing (e.g., via telephone or around the dinner table), and institutional contexts include medical, legal, entertainment, and political arenas (e.g., doctorpatient consultations, courtroom cross-examinations, and TV talk show interviews, among others). We drew upon well-established CA corpora (publically available online via TalkBank; MacWhinney 2007), in addition to our own and colleagues' datasets (see Acknowledgments), in making our collection, which includes both audio- and video-taped interactions. We began by systematically gathering all references to time present in the data, generating a collection of approximately 250 time reference formulations. Our focus in assembling the corpus was to collect the widest range of forms and uses of time references in naturally-occurring interaction.

Conversation Analysis as a method seeks to understand the systematic ways in which interactants design their contributions to talk for particular recipients at particular moments in the service of social action (see Heritage 1984). As we began an inductive examination of our collection of time references, we followed previous interactional research on person and space 
reference (e.g., Enfield 2013; Levinson 2003; Sacks \& Schegloff 2007[1979]; Stivers 2007) in focusing on the form of the reference within turns-at-talk (see Sidnell 2013 for an overview of basic conversation-analytic methods). From these preliminary delineations by design, our next task was to determine if discrete social affordances could be linked to those different formulations - that is, linking form to function (e.g., Bolinger 1977). The challenge was to uncover categories that were not only demonstrably relevant to and meaningful for the individuals engaging in interaction, but also mutually exclusive to merit the creation of a taxonomy. We continued to collect additional data and revise our categorizations until a point of saturation was reached where any new time reference formulation collected could be readily situated within our taxonomy. The excerpts included for discussion here were selected due to their representativeness of the several hundred reference formulations that populate our overarching dataset.

\section{A TAXONOMY OF TIME REFERENCES AND THEIR SOCIAL AFFORDANCES}

Our taxonomy makes a distinction between what we term Absolute and Event-Relative time references, with each category being subdivided.

\section{Absolute Time References}

An Absolute time reference, as we define it, is a reference form which is accessible to all through its use of shared constructs for parsing the timeline. By 'shared constructs', we refer to concepts such as an 'hour', a 'day' or a 'year', as well as clock time (e.g., 'at 3:45') and calendar time (e.g., 'March $30^{\text {th }}$ of 1987 '), which are "recognizable, in principle, by all members of the speech community" (Fillmore 1997:49) and "have a high degree of social objectivity" (Luckmann 1991:157). 
Context dictates the additional significance that any particular reference may have-e.g., whether 'at 3:45' is a long or short wait from now (Button 1987; Flaherty 1999), whether or not it is a convenient time to meet up, or if it will imply leaving before rush-hour traffic_-given that, as James (1922:623) observes, "each hour in the day has for most of us some outer or inner sign associated with it" (cf. Adam 1995:21 on "good' and 'bad' times for action"). Similarly, Churchill (1966) notes that different quantifications of clock-time can convey varying levels of “approximateness vs. preciseness” (e.g., 'I'll be back at 3:45' vs. 'I'll be back at 3:47'), which can indeed be consequential for the participants' understanding of the reference. Nonetheless, at the surface level, a reference like 'at $3: 45$ ' is objective, devoid of connotation, and therefore Absolute. $^{4}$

This surface-level objectivity is an intrinsic affordance that Absolute TRs provide. In the same way that using a proper name to refer to a person saves speakers from having to choose a (potentially contestable) description of the individual in question (Searle 1958), Absolute TRs allow speakers to make cuts on the timeline that are presented as independent of circumstantial detail.

While we will provide contextualized analyses of TR formulations and their impact on the social actions of turns-at-talk in a later section, here we offer decontextualized examples of Absolute TRs simply to illustrate the terminology.

01 DAD: You will- you will be back about four o'clock huh?

${ }^{4}$ Our use of the term 'Absolute' is borrowed from Levinson's (2003) work on references to space. The canonical examples of Absolute space references are cardinal directions, such as north, south, east, and west. We see a parallel in the surface-level, seemingly objective use of cardinal directions and calendar/clock time: 'At 3:45' may have additional connotations (e.g., inconvenience due to traffic), in the same way that relocating 'west of the 405 freeway' in Los Angeles may invoke additional connotations such as affluence and opportunity. Thus while we recognize that any reference form can be colored by circumstantial detail in its specific context, we maintain that, as a category, Absolute reference forms' surface-level neutrality is nonetheless oriented to by participants as an affordance in interaction. 
01 NAC: I thought you were going in like an hour.

As the above examples (2)-(4) illustrate, while Absolute TRs point to a specific time on the timeline in relation to 'now', they differ in terms of the unitization of the time being referenced, and hence the specificity of the moment being targeted. For instance, although both 'March $30^{\text {th }}, 1987^{\prime}$ and ' $1987^{\prime}$ ' are both situated points on the timeline, the former involves a smaller unit of duration and hence a greater degree of granularity in targeting an exact moment than does the latter (cf. Zerubavel 1976:89) . $^{5}$

Within Absolute time references, two subcategories can be distinguished that we will refer to as Uncounted and Counted. Uncounted references refer to a time but do not calculate for the hearer the distance from the speech event ('now') to that time (e.g., 'on March $30^{\text {th, }}$ ' at $5: 45$ ', etc.). Counted references, on the other hand, do calculate the distance from 'now' to the referred time (e.g., 'two nights ago,' 'in three and a half hours,' etc.). It should be noted that, while the default frame of reference is typically calculated from a present-centered 'now' (the deictic center or 'coding time'; Fillmore 1997), speakers can alternatively work to dislocate this default by re-anchoring the point in time from which the TR is calculated (e.g., 'I got home at 5pm and ten minutes later Alice walked in the door' ${ }^{6}$ ) (cf. Elias 1992).

Counted time typically includes a quantity and a unit of duration of time. While this quantity is most often expressed in numerical terms, various lexicalizations exist for different

\footnotetext{
5 The issue of granularity also applies to Event-Relative TRs.

${ }^{6}$ Similarly, 'Ten minutes after I got home' constitutes a combination of an Absolute TR and an Event-Relative TR that also re-anchors the point in time from which the Absolute TR is calculated.
} 
amounts of time. ${ }^{7}$ For example, at the level of the 'day', 'one day ago' is lexicalized to 'yesterday' and 'one day from now' is lexicalized to 'tomorrow'.

A basic affordance of Counted references is the speaker's ability to select which unit of measurement $\mathrm{s} / \mathrm{he}$ will use to reckon time. Although these units of measurement are intersubjectively standardized, this selection (e.g., 'six months' vs. 'half a year') can nonetheless serve to frame the hearer's conceptualization of the temporal referent. Furthermore, counted time opens up the possibility for speakers to agentively shape the duration of the referenced time (see Flaherty 2011), for example, by rounding, approximating, exaggerating, minimizing, and so on (Churchill 1966; Drew 2003): 'Six weeks' can become 'just over a month' (to diminish) or 'nearly two months' (to expand). Uncounted references, by contrast, have the affordance of not requiring the speaker to select a unit of measurement or evaluate its duration, thus allowing the hearer to calculate temporal distance for him/herself.

While Uncounted and Counted Absolute TRs differ because of the calculation that the latter undertakes but the former does not, they have in common that subjective distance depends on context. In fact, all time reference formulations (both Uncounted and Counted Absolute TRs, in addition to the Event-Relative designs described in the next section) are characterized by this contextual variability. To take a Counted Absolute TR as a case in point, 'seven months ago' could be used to convey temporal distance in the context of describing how long milk has been in the refrigerator, but it is not intrinsically a 'distant' time reference (cf. Garfinkel 1967). That is, one can easily imagine an utterance such as 'I bought my car seven months ago, and it broke down today', in which the same TR design is specifically employed to accomplish temporal

\footnotetext{
${ }^{7}$ We categorize lexicalized expressions for the present day (e.g., 'today', 'this morning', 'tonight') as Counted Absolute TRs due to their counting of an implicit 'zero'. Similarly, 'next' and 'last' are Counted Absolute TRs due to their counting of an implicit 'one'.

${ }^{8}$ These lexicalizations are language- and culture-specific. See, for instance, Fillmore (1997:71) on Chinantec; Whorf (2002[1940]) on the Hopi.
} 
proximity. Thus, in Sorokin and Merton's (1937:622) words, such “quantitatively equal periods of time are rendered socially unequal" depending on "the nature and intensity of their qualities". In sum, then, there is no one-to-one relationship between TR design and subjective distancing.

\section{Event-Relative Time References}

Thus far we have discussed ways of referring to time by using calendar or clock time, or unitized versions of those. Nonetheless, as Adam (1995:21) describes:

The existence of clock and calendar time does not prevent us from locating the past, present, and future with reference to events, processes, and social relations...That is to say, the existence of clock time, no matter how dominant, does not obliterate the rich sources of local, idiosyncratic, and context-dependent time awareness which are rooted in the social and organic rhythms of everyday life.

The defining feature of what we term Event-Relative time references is the incorporation of a direct reference to some event in the social world. For instance, in lieu of using 'March $30^{\text {th }}$, (an Uncounted Absolute TR), a speaker may make reference to 'Oliver's birthday'. The following are examples of Event-Relative TRs. Again, these are decontextualized instances to help illustrate the terminology.

(5) NBII : $1: R: 6$

308 LOT: eh wu-u-when: $1:$ Ei:senhower was in there'e didn'do

309 a hell'v a lo:t .hhh but by God those countries were

310 afräid of us he kept us outta wạ:r anyway.

(6) (Robinson 2014:121)

EMM: Had they been working on finding a place for you to li:ve: (.) before you got there? or

01 CAR: I haven't had Chipotle since the last time we had Chipotle.

Note that by event-relative, we do not mean simply event-related. For instance, both the Event-Relative TR 'when Clinton and Trump had their first presidential debate' and the Absolute 
TR 'on September $26^{\text {th }}, 2016^{\prime}$ ' are of course related to the debate. Nonetheless only the former is 'event-relative' in its form due to its inclusion of the event in the construction of the reference itself. ${ }^{9}$

Event-Relative TRs, in addition to invoking an event in their construction, may also include a person who is connected to that event, thus potentially coloring the reference with causality. In example (5) above, "when: 1:Ei:senhower was in there" invokes President Eisenhower as being responsible for "those countries [being] afraid of us" in a way that the Absolute design 'from 1953 to 1961' would not. Indeed, the speaker makes this connection explicitly with "he kept us outta wa:r anyway". Thus while the design of Absolute TRs affords speakers the ability to reference time using methods that are, at the surface level, devoid of connotation, Event-Relative TR formulations allow speakers to imbue their cuts on the timeline with additional connotation by way of an event's inclusion in the reference itself (cf. Sorokin \& Merton 1937:618). This additional social meaning can then be mobilized toward the accomplishment of the speaker's interpersonal and action-based goals.

Examples (5)-(7) above have in common the reckoning of time through the use of an anchoring event in the reference. However, they differ with regard to whose epistemic/experiential domain the anchor is located in. We categorize Event-Relative TRs in accordance with interactants' relative rights and obligations to knowledge of, or experience with, the event (Heritage 2012; Heritage \& Raymond 2005; Kamio 1997; Labov \& Fanshel 1977:100101):
a. Shared between interactants (Jointly-Framed)
b. Speaker-centered (A-Framed)

\footnotetext{
${ }^{9}$ Additionally, calendar dates, which on the surface appear to be straightforward Absolute TRs, can occasionally be events that do not reference time. For example, "The terrorist attack planned was to be the next 9/1 1" (NPR, February 21,2013) uses a calendar date to invoke an event but does not cut the timeline.
} 
c. Recipient-centered (B-Framed).

\section{Jointly-Framed Event-Relative TRs}

Jointly-Framed Event-Relative time references project neutral epistemic/experiential territory between interactants. Within this category there is a further subdivision between $O$ Framed and AB-Framed designs. O-Framed TR designs include events that are public, social facts that exist outside of the individual (Durkheim 1951[1897]), including community knowledge (e.g., (5) “when Eisenhower was in there"), and cultural events (e.g., 'on Christmas'). AB-Framed TRs include interpersonal events known to the co-participants (A and B) but not necessarily to the community at large (e.g., (7) "the last time we had Chipotle"), and both interactants share equal access to and knowledge of the event. As a class, Jointly-Framed EventRelative TRs are similar to Absolute TRs in that the cut on the timeline is projected to be accessible to both the speaker and hearer. Nonetheless, Jointly-Framed Event-Relative TRs are not devoid of connotation at the surface level as are Absolute TRs, but rather allow the speaker to convey additional meaning by tapping into the significance of the event used in the reference, as seen in the Eisenhower example.

\section{A- and B-Framed Event-Relative TRs}

Distinct from Jointly-Framed events, are events situated primarily on the speaker's ( $A$ Framed) or hearer's (B-Framed) personal timeline-for example, 'after my exam' and 'after your exam,' respectively. Note that when a speaker refers to an event on a recipient's timeline, the recipient nonetheless maintains epistemic and experiential primacy over that event (cf. Raymond \& Heritage 2006; see also Button 1987 and Sacks 1988/89 on "private calendars").

Anchoring time in one's own timeline or in that of one's interlocutor is comparatively higher risk than Jointly-Framed or Absolute reference forms. A-Framed designs project that the 
hearer possesses a certain level of access to the speaker's life, and B-Framed designs claim a certain level of access to the hearer's life (cf. Levinson 2003:33). If a speaker mobilizes one of these TR forms in an unrecognizable or otherwise inapposite way, they may find themselves, in Goffman's terms, unable to keep their line: The reference may misfire, not only undermining the social action of the utterance, but also potentially damaging the participants' social relationship through threats to face. Nonetheless, if successful, the benefit of A- and B-Framed TRs is that they afford speakers the opportunity to embody and promote face-affirming intimacy with their interlocutor at the micro-interactional level. An example of success is seen in excerpt (8) in which Hyla is making plans with her best friend, Nancy, to attend a staged version of her favorite movie. Hyla situates the first performance in relation to her own birthday.

(8) HGII

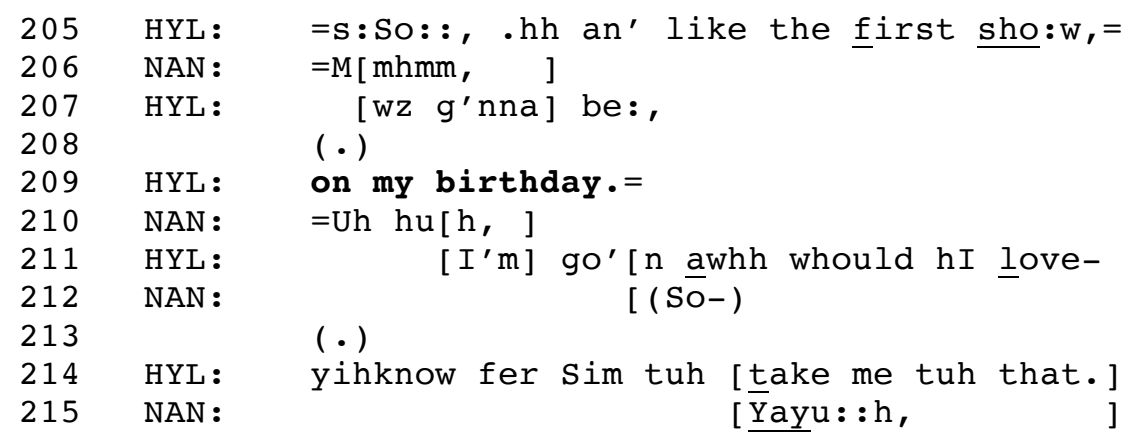

Hyla's A-Framed TR projects that her friend will be able to situate "my birthday" in time, and indeed, Nancy's immediate latched continuer "Uh huh," (line 209) demonstrates that this reference form is unproblematic for her. The fact that Hyla is able to reference an event from her personal timeline and that Nancy accepts it, serves as a micro-level reaffirmation of their close friendship. This A-Framed TR is thus face-affirming for both co-participants through this positive relationship work. 


\section{Summary of Affordances}

In establishing this taxonomy, we have described the divergent social affordances that distinct time reference formulations provide interactants. These are summarized in Table $1^{10}$ :

\section{[TABLE 1]}

Time references-no matter what their formulation-are components of turns-at-talk and are thus mobilized in the service of social action. While for some utterances, referencing time may be the explicit objective of the talk (e.g., organizing when two friends plan to meet), time references can be interwoven with a variety of other actions as well (e.g., requesting, hinting, story-telling, etc.), in addition to contributing to the more overarching goals that are associated with those actions. In all cases, understanding the affordances invoked by distinct TR designs grants us insight into why a speaker may select one formulation over other equally 'correct' options.

Let us provide a concrete example in which a specific time reference contributes to the action being undertaken by the speaker. In excerpt (9), Gordon, who is away at college, calls his mother, Leslie, to request that she bring him a letter on her upcoming visit. The dispreferred, potentially face-threatening nature of requests is evident in the difficulty with which Gordon constructs his turn (lines 7-10) (Brown \& Levinson 1987). The requesting action is then ultimately mitigated through the addition of the B-Framed Event-Relative time reference in line 10.

\footnotetext{
${ }^{10}$ While this table provides an overview of time reference formulations and their affordances, one must bear in mind that references to time are always produced within a contextual and sequential environment which, as our analysis will show, render them meaningful in particular ways for participants.
} 
(9)

$\begin{array}{ll}01 & \text { LES : } \\ 02 & \\ 03 & \text { GOR: } \\ 04 & \text { LES : } \\ 05 & \text { GOR: } \\ 06 & \\ 07 & \text { GOR: } \\ 08 & \\ 09 & \\ 10 & \end{array}$

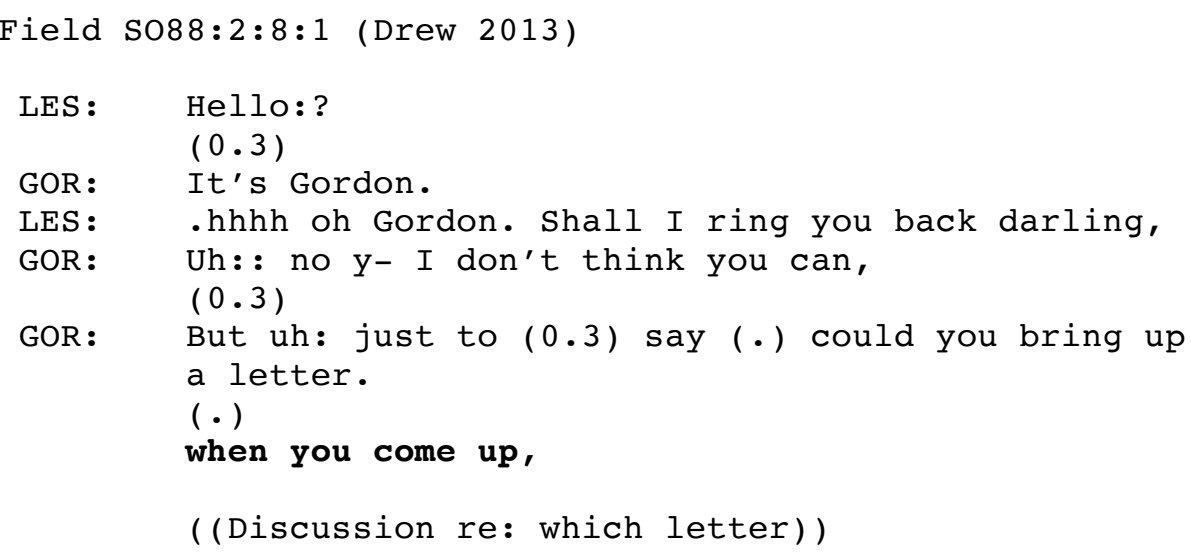

The B-Framing of the TR in line 10 affords Gordon the ability to reduce the contingencies associated with granting the request (Clayman \& Heritage 2014; Curl \& Drew 2008) by indexing his belief that Leslie has already scheduled a visit. Because no special arrangements need to be made, the addition of the increment ("when you come up,") works to present the burden on Leslie as significantly reduced. Thus, although the time reference is tacked on at the end of the request and may initially appear ancillary to Gordon's action agenda, the affordance that the BFramed TR design provides is what ultimately works to depict the request as minimally intrusive.

\section{TAXONOMIC FORMS IN ACTION}

In the preceding section, we sketched the taxonomy and illustrated with a brief example how the inclusion of a single time reference, with a particular design, can contribute to a speaker's aims. We now move on to examine cases in which the same cut on the timeline is made through more than one taxonomically distinct TR formulation. This may be speakerdriven, in order to make use of the affordances provided by each TR, or it may be responsive to interactional moves by the hearer. Nonetheless, in all cases, a speaker's mobilization of multiple reference formulations demonstrates interactants' understandings of [i] TR designs as being 
distinct, and [ii] the affordances provided by those different designs. Such cases therefore provide us with added traction in identifying linkages between TR design, affordances, and uses in accomplishing social action.

\section{Mobilizing Multiple Affordances}

A speaker's action agenda can make relevant more than one TR formulation in order to mobilize the affordances provided by each. In example (10), taken from a July 2010 appearance on The View, President Barack Obama aims to convince his interviewers, the audience, and also the millions of at-home viewers, that there exists a set plan to remove troops from Afghanistan. In doing this, he adds a Counted Absolute TR to complement his Uncounted Absolute TR in line 2.

(10) The View, 7-29-10

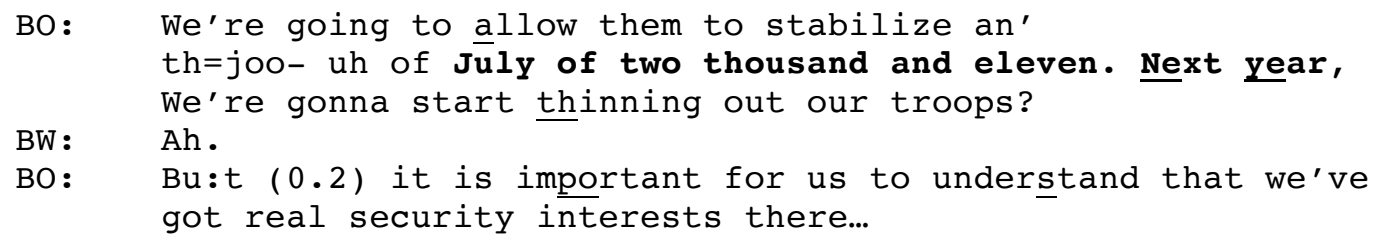

Obama's first TR — an Uncounted Absolute "July of 2011" — cites a specific calendar date for the removal of troops to which he can be held publically accountable. The granularity of not only a year but a particular month reinforces the specificity of this plan as an official, on-record commitment (Churchill 1966; Clayman \& Romaniuk 2011), which given the nature and rhetoric of promises to end wars, may require defense. Obama then goes on to add "next year," a Counted Absolute TR. Counting the distance affords Obama the opportunity to sway his listeners into perceiving the original "July of 2011" as right around the corner. Note that this interview was conducted in July of 2010. The "next year", 2011, is only six months away, while Obama's proposal is eleven months away: By including "next year" Obama mobilizes a time reference to 
minimize the distance between the speech event and the removal of troops. It is the consecutive use of an Uncounted and a Counted Absolute TR which therefore maximizes the accomplishment of Obama's goal to demonstrate commitment to a plan that is specific and soonto-be-realized. We can therefore see Flaherty's (2011) "time work" - the effort to control, manipulate, or customize temporal experience — being realized here in and through Obama's choice of time references.

While both temporal proximity and distance can be evoked by Absolute and EventRelative TRs, the use of Event-Relative formulations is distinctive in contextualizing the significance of that proximity or distance. Excerpt (11) is taken from the cross-examination of the victim in an assault trial. The trial is occurring several months after the attack, and at this point in the cross-examination, a discrepancy arises between the victim's current testimony and her original incident report. In an attempt to discredit her testimony, the District Attorney accuses the victim of adding new details to her account (namely, the use of her purse as protection).

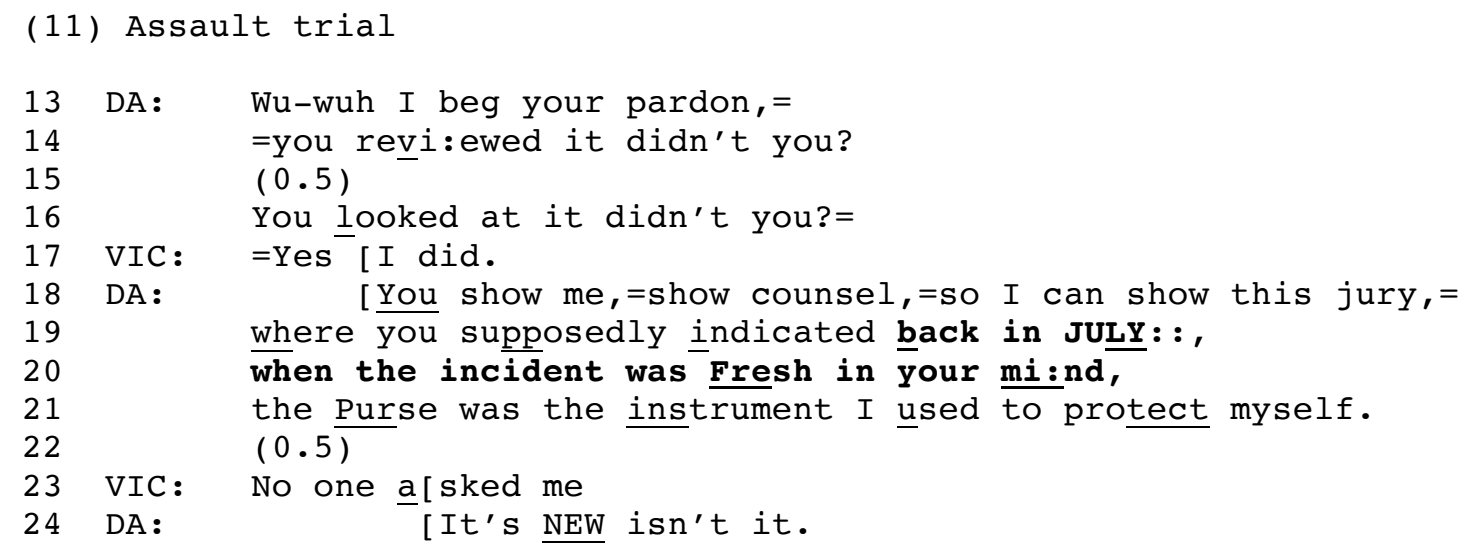

The first formulation—“Back in JULY::," (line 19)—constitutes an Uncounted Absolute TR. This indicates a point on the timeline which serves to emphasize the distance between her original police statement and the present day in court, and also the proximity to the original 
incident. Nonetheless, this TR alone does not overtly account for why the distance is relevant: The import of making the cut at "July" would be left for the jury to infer. By adding the EventRelative TR "when the incident was Fresh in your mi:nd", the DA effectively does this work for the jury by explicitly stating the relevance of the referenced time: Her original report was closer to the alleged incident and hence reflects an ostensibly "fresh[er]" and more accurate version of what transpired. This combination of reference forms to reckon time thus actively contributes to the DA's attempt to discredit the witness's testimony.

\section{Pursuing Intersubjectivity}

In the preceding section, multiple time references were mobilized in the service of interactional goals. However, initial TR formulations can also fall short or misfire in various ways and/or fail to receive desired uptake. Difficulties of hearing or understanding an utterance containing a time reference not only problematize the TR itself, but simultaneously jeopardize the turn's overarching social action (see Schegloff, Jefferson \& Sacks 1977), and may also constitute threats to the participants' face. In response to such instances of interactional trouble, speakers can reformulate and offer a new TR formulation.

Recall example (1) above from the history-taking phase of a doctor-patient interaction, repeated here as (12). In this excerpt, the doctor asks the patient how long she has been "drinking that heavily" (line 1). In response to her initial A-Framed Event-Relative "Since I've been married", the doctor seeks clarification which serves as the catalyst for the patient's reformulation to an Absolute design "Four years".

\footnotetext{
01 DOC: How long have you been drinking that heavily?

02 PAT: Since I've been married

03 DOC: How long is that?

04 PAT: ((giggle)) Four years
} 
While the patient's line 2 responds to the doctor's question, the Event-Relative design of the TR resists the question's medical agenda and instead uses this opportunity to situate her drinking in her own lifeworld (Mishler 1984). Although this A-Framed formulation affords the patient the ability to insinuate a causal association between her drinking habits and her marriage, it fails to situate where this point is in time for the doctor. In response, the doctor inquires, "How long is that?" (line 3), to push for a more accessible and medically relevant time reference that he can use to assess the patient's health. The patient's subsequent production of an unambiguously interpretable Counted Absolute TR ("Four years") then conforms more strictly to the medical agenda of the question. Reformulating her turn with a taxonomically distinct TR also reveals the patient's understanding that it was specifically the design of her initial time reference which led to the hitch in intersubjectivity, with the turn-initial giggle in line 4 likely attending to the interactional (and medical) misdeed of her previous turn (Haakana 2001; Jefferson 1984). By the end of this sequence, given that a repaired reformulation cannot completely erase the original design (Jefferson 1974), the two distinct time references have effectively allowed the patient to convey both the extent and the background of her drinking habits.

While it is not surprising that A-framed Event-Relative TRs can be the source of interactional trouble due to their being situated on the speaker's personal calendar, B-framed formulations are not immune to problematization by hearers. This is seen in (13) in which Emma informs her daughter, Barbara, that she has quit smoking. Barbara asks when the quitting began, and her mother responds with a B-framed Event-Relative TR (line 158).

(13) NB : IV : 7

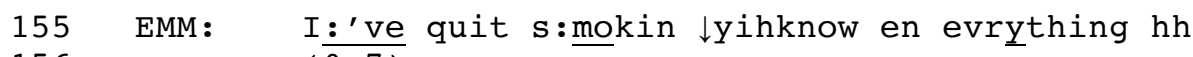




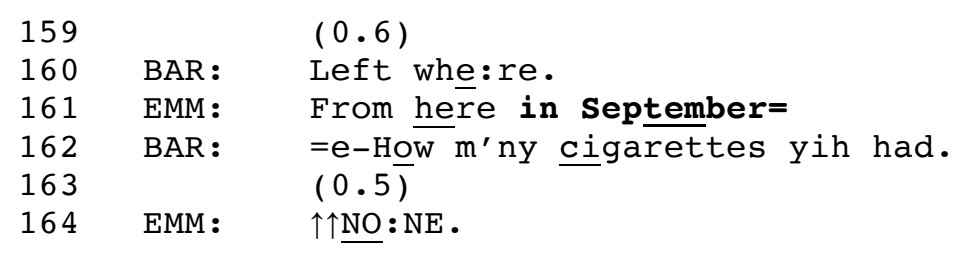

Emma formulates her response to her daughter's question as an emphatic "THE DAYY Y $\underline{O U}$ LE:FT.h" (line 158). Actively invoking Barbara as the subject of this B-framed Event-Relative TR at minimum allows Emma to invoke a connection between Barbara's visit and the decision to quit smoking, and the specificity of an exact day underwrites the truth of the report. Here, though, Barbara has trouble interpreting the reference for meaning and problematizes Emma's TR with a delayed "Left whe:re." (line 160), which may also reflect confusion over being implicated in her mother's decision to quit smoking. Notwithstanding, Barbara's turn jeopardizes the success of Emma's overarching announcement-in-progress. In response, Emma provides both a 'where' as well as a more recognizable (via an Uncounted Absolute TR) 'when'—“From here in September" (line 161) —in an effort to salvage the causal association initially attempted with

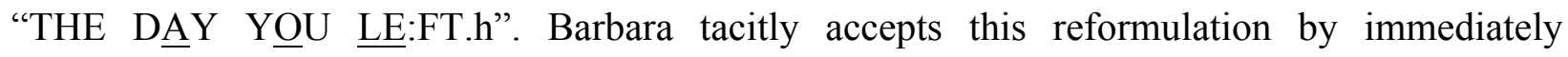
progressing the conversation in the next turn.

While the previous two examples added Absolute TRs in response to overtly problematized Event-Relative designs, shifts can occur the other direction as well. In example (14), brothers Kyle and Daniel are discussing Daniel's viewing of the film The Godfather. Of particular interest to them is when this viewing occurred.

(14) (Fox and Thompson 2010)

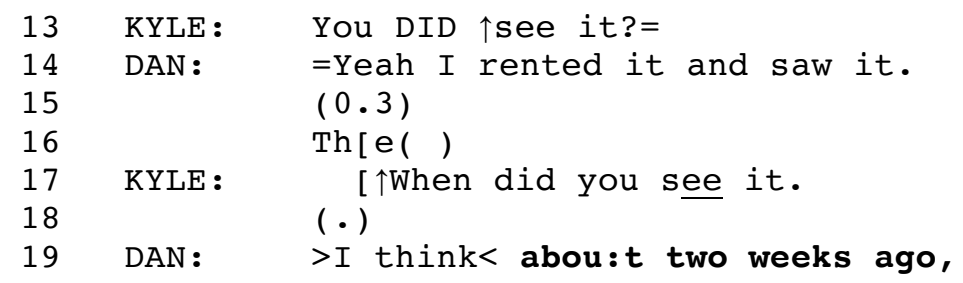




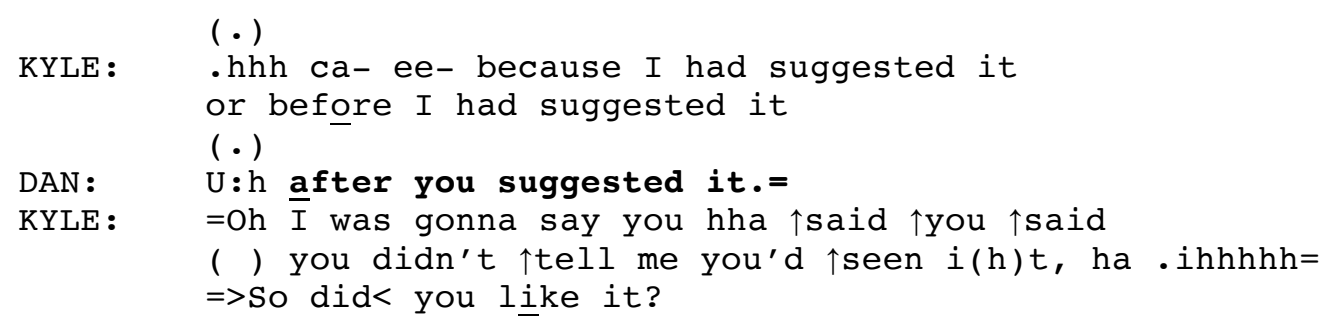

Daniel's initial Counted Absolute TR “abou:t two weeks ago," (line 19) directly conforms to both the topic and the surface-level agenda of Kyle's question. However, this formulation fails to recognize any connection between Kyle's previous suggestion and Daniel's viewing. Because the suggestion also occurred "abou:t two weeks ago,", Kyle inquires as to whether Daniel watched it before or after he suggested it, as it would have been peculiar for Daniel not to have alerted his brother (at the time) that he had already seen the movie being recommended (lines 2527; Sacks 1992). That is, Kyle seeks to re-anchor the initial time reference as an Event-Relative TR in search of recognition of his recommendation (lines 21-22). Daniel accepts this framing and provides a reference form that now includes Kyle in its design: "Affter you suggested it" (line 24) thereby not only accomplishes the action of informing, but also actively 'does giving credit' to Kyle (Sacks 1984).

While hearers may play an active role in eliciting a subsequent TR design, as seen in examples (12)-(14), a lack of uptake (see Pomerantz 1984) can also serve as the impetus to initiate a new time reference formulation. Example (15) comes from a 2008 ABC Nightline interview with then-Vice-Presidential nominee, Sarah Palin. In this interaction, the interviewer, Charles Gibson, asks Palin if she supports "the Bush Doctrine"11 (line 1). In response, Palin makes an open-ended request for clarification: "tch .hhhhhhh In what respect Charlie," (line 3). Gibson begins to provide clarification in line 5 before countering to ask Palin's own

${ }^{11}$ The National Security Strategy of the U.S., published in 2002 and revised in 2006, is often cited as the "Bush Doctrine" and states "...to forestall or prevent such hostile acts by our adversaries, the Unites States will, if necessary, act preemptively in exercising our inherent right to self-defense". 
interpretation of the doctrine. Palin's upwardly intoned response in line 8, "tch His worldview," is rejected by Gibson who then uses time references to provide hints for Palin so that she can answer his initial question.

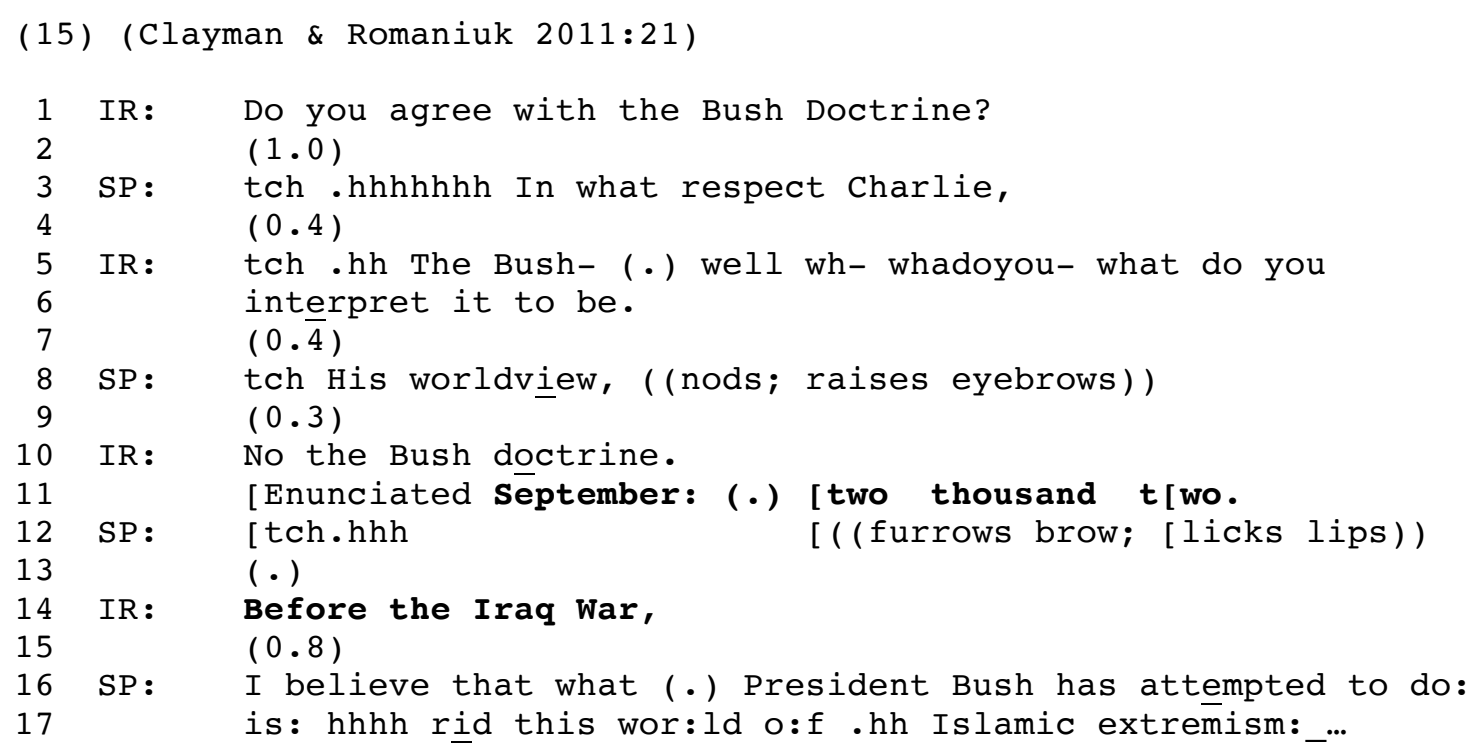

In line 10, Gibson's Uncounted Absolute TR, “September: (.) two thousand two.", emphasizes his referring to one of Bush's specific foreign policies—not a vague idea of his overall "worldview" (line 8). This TR, devoid of connotation at the surface level, affords Gibson the opportunity to simply make a cut on the timeline without conveying any additional information to Palin. The use of this TR presupposes - or, as appears to be the case here, tests-Palin's recognition of the date's relevance to the topic at hand (lines 1, 5, 10). Furthermore, this initial TR is prosodically drawn out (elongation, micro-pause), allowing Palin significant opportunity to come in in overlap to display her understanding.

In the environment of these repeated failures, together with a series of facial expressions from Palin suggestive of incomprehension (lines 8-13), Gibson adds an O-Framed EventRelative TR in the form of an increment: "Before the Iraq War," (line 14). This explicit temporal connection between the enunciation and a direct outcome of this policy serves to give Palin an 
additional clue as to the nature of "the Bush Doctrine". In moving from the objectivity of an Absolute TR, which evidently lacks relevant meaning for Palin, to a TR infused with significance via a global event, Gibson progressively increases the chances that Palin will recognize the referent and therefore be able to answer his initial question.

Whether problematized implicitly or explicitly, threatening the success of a time reference simultaneously threatens the social actions being attempted within the sequence, as well as can have ramifications for the interactants' face. When this occurs, speakers actively work to resolve the break in intersubjectivity and salvage the course of action underway. By analyzing examples that include multiple TR formulations, we are able to track and pair taxonomically distinct time reference designs with the affordances they provide.

\section{DISCUSSION}

\section{Time Reference and Reference More Generally}

In researching references to persons in English conversation, Sacks and Schegloff (2007[1979]) describe a difference between reference forms that are default or 'unmarked', and those that are 'marked'. While unmarked forms convey that "nothing but referring is being done" (Schegloff 1996:439), marked forms do more than "just refer", deviating from the default in conjunction with particular social aims (see Fox 1987; Stivers 2007).

By contrast, in examining references to time in interaction, we can discern no default design. Our data suggest that no time reference formulation is without implications for social action. That is, it is not the case that Absolute TRs, for example, are the unmarked default from which Event-Relative TRs constitute a deviation. Rather, all time reference designs, as we have illustrated, do more than "just refer" by contributing to the social action being undertaken in the 
turn. This is due to the intrinsic affordances inherently provided by differing formulations which speakers mobilize in accordance with their interactional goals.

\section{Distribution of Reference Forms}

In assembling a collection of time references in naturally-occurring interaction, it is noteworthy that we encountered B-Framed Event-Relative designs relatively infrequently. We posit two possible explanations for this distribution. The first relates to knowledge: Speakers always have access to their own personal timelines as well as access to shared constructs for parsing time, and thus the possibility of referencing time using A- and Jointly-Framed EventRelative TRs, and Absolute TRs, pervades. Because speakers are not always privy to their interlocutor's calendar, oftentimes they may simply lack the resources with which to formulate B-Framed references, thereby generating a relative dearth of such TRs.

A second explanation may be found in what Heritage (2011) refers to as "territories of knowledge and experience" (cf. Kamio 1997). Even if a speaker possesses knowledge of a hearer's calendar, s/he may be reluctant to actually mobilize that knowledge, as claiming access to a hearer's timeline might be perceived as inappropriately intrusive. Indeed, this explanation finds common ground with research on interactants' orientations to their respective rights more generally, as reflected in turn design: Speakers can be seen to actively work to not intrude into a hearer's epistemic or experiential domain (see Heritage 2012). ${ }^{12}$ Even amongst friends, too much other-attentiveness can come across as overbearing or over-attentive (Heritage 2011; Raymond \& Heritage 2006). The fact that B-Framed TRs are rare even in interactions in our corpus

\footnotetext{
12 For example, in the following excerpt, Leslie initiates self-repair (from declarative to interrogative syntax; Heritage 2012) to avoid presuming knowledge about Hal and his life:

Field S088(II): 1:3:1 (Drew 2013)

LES: .hhhh I RANG you up-(.) ah: think it wz la

2 But you were- $\overline{(\cdot)}$ u-were you ou:t?
} 
between friends and family members (who are most likely to possess the knowledge needed to formulate B-Framed TRs) suggests that their relative infrequency may be at least partially motivated by such concerns.

\section{Time Reference and Time-Reckoning Systems}

While social scientists have long been interested in the existence and evolution of timereckoning systems, here we have described the concrete language practices through which references to time are invoked by members of society. Yet these are not mutually exclusive inquiries. The historical development of time-reckoning systems is inextricably linked to how time is referred to in interaction.

For instance, by the end of the fourteenth century, the bells used by Benedictine monks to organize their daily activities had gained a presence in the adjacent countryside and marketplaces (Adam 1995; Giddens 1991; Roy 2001; Zerubavel 1981), thereby affording nearby residents the ability to also coordinate their lives with the increased granularity now available through reference to routinized bell tolls. That is, the availability of this new auditory measure of time altered the landscape of affordances as individuals could articulate time references from an augmented repertoire. As community bell towers evolved to community clock towers, the palette of reference formulations was again transformed as yet another novel resource for parsing the day became available to social actors. It can be argued, therefore, that one crucial way that historical developments such as bell or clock towers are able to impact a society is through the design of references to these time-reckoning technologies in moment-by-moment interaction. That is, it is not merely the existence of timekeeping technology itself that affects society, but rather the effect that such technology has on the palette of options used by interactants to situate themselves and others in time. 


\section{CONCLUSIONS AND AVENUES FOR FUTURE RESEARCH}

Here we have shown that time-reckoning as a social practice is not an abstract notion, but rather must be "talked into being" (Heritage 1984) at the ground level of situated interaction as co-participants select time reference formulations in the service of action. Our analysis thus enables us to recognize that Durkheim's (2008[1912]) notion of time as collectively organized, Elias's (1992) and Flaherty's $(1999,2011)$ preoccupation with the constraints and manipulation of time, and Luckmann's (1991) conceptualization of time as consistently re-achieved in face-toface-interaction, are all fundamentally rooted in the practices that social actors use to refer to time in talk. Time-reckoning is thus necessarily embodied, instantiated, and inscribed in the concrete use of time references in social interaction, as members of society collaboratively achieve the temporal coordination that Garfinkel (1967) posited is so crucial to the constitution and recognition of action and understanding.

In sum, our analysis illustrates that, while there are many ways to formulate what may be conceptualized as the 'same' cut on the timeline, all are not socio-interactionally equal. As Sacks (1988/89:51-52) observed: "A list of equivalences is not to be made by virtue of such a thing as: 'Pick a correct answer. Get a list of correct answers. Any one of them is okay by virtue of being correct.' That's just not the way it works". On the contrary, as we have demonstrated here, speakers make time reference selections for a reason, and hearers, in turn, orient to those formulations as having been produced 'for cause'. And to continue the quote from Sacks, "you are only at the point where sociology is interesting when you can see that".

The taxonomy we have developed offers a variety of avenues for future research. Early work by Mead $(1932,1936)$, for instance, argued that social actors not only use the past to create interpretations of the present, but also that it is through our interactions in the present that we 
generate interpretations of the past. As was particularly evident in our analysis of the DA's questioning in the assault trial (case (11)), the specific design of references to time constitutes one concrete means to actively engage in this interplay between present, past, and future, something which future research may seek to further unpack.

The taxonomy we provide may also inform research in a variety of other disciplines wherein timing and temporality are of critical import. Take, for example, recent inquiries into palliative care contexts, specifically the various dilemmas that doctors face when having end-oflife discussions (see, e.g., Parry, Land \& Seymour 2014): How do/should doctors answer the question 'How long do I have left to live?', and how do patients and their family members respond to differently formulated TR designs in such interactions?

The diagnosis of various autistic spectrum disorders (ASD) may constitute another site of possible application of the present work: Such diagnoses are reached not through genetic testing, but through communication- and behavior-based tasks (Turowetz \& Maynard 2016). Given that many children with ASD display a "preoccupation with clocks and chronology" (Solomon 2004:260), might the predominance (or absence) of certain TR formulations be incorporated as a diagnostic criterion in these encounters?

In addition, in investigating how children acquire a conceptualization of time (e.g., Tillman \& Barner 2015), what new directions might distinguishing between Absolute and EventRelative designs, or perhaps between distinct levels of granularity within one taxonomic category or another, offer developmental psychologists?

It is our hope that the micro-interactional perspective on timing and temporality that we offer here will enable a wide range of researchers to interpret their own phenomena of interest in new ways. Because making reference to time constitutes such an integral part of everyday human 
sense-making, continued exploration of the micro-level practices for doing so will shed important light on an essential aspect of how we construct and maintain social life with one another. 


\section{REFERENCES}

Adam, Barbara. (1995). Timewatch: The Social Analysis of Time. Cambridge: Polity Press.

Anderson, Stephen R., \& Keenan, Edward L. (1985). Deixis. In Timothy Shopen (Ed.), Language typology and syntactic description, 259-308. Cambridge: Cambridge University Press.

Astington, Janet W. (2006). The developmental interdependence of theory of mind and language. In N.C. Enfield and Stephen C. Levinson (Eds.), Roots of human sociality (pp. 179-206). London: Berg.

Atkinson, J.M. \& John Heritage (Eds.). (1984). Structures of Social Action: Studies in Conversation Analysis. Cambridge: Cambridge University Press.

Berger, Peter L., and Thomas Luckmann. (1967). The Social Construction of Reality. Garden City: Anchor Books.

Bergmann, W. (1992). The Problem of Time in Sociology An Overview of the Literature on the State of Theory and Research on the Sociology of Time, 1900-82. Time \& Society 1:81134.

Bergson, Henri. (1971[1910]). Time and free will. London: George Allen \& Unwin Ltd.

Bolinger, Dwight. (1977). Meaning and form. Longdon: Longman.

Brown, Penelope, \& Levinson, Stephen C. (1987). Politeness: Some universals in language usage. Cambridge: Cambridge University Press.

Button, Graham. (1987). On member's time. In Bernard Conein, Michel de Fornel \& Louis Quéré (Eds.), Les formes de la conversation, 161-182. Paris: CNET.

Churchill, Lindsey. (1966). Notes on Everyday Quantitative Practices. Paper presented to the American Sociological Association Meeting, Miami Beach, Florida.

Clark, Herbert H. (1996). Using language. Cambridge: Cambridge University Press.

Clayman, Steven E., \& John Heritage. (2014). Benefactors and beneficiaries: Benefactive status and stance in the management of offers and requests. In Paul Drew \& Elizabeth CouperKuhlen (Eds.), Requesting in Social Interaction, 55-86. Amsterdam: John Benjamins.

Clayman, Steven E., \& Tanya Romaniuk. (2011). Questioning Candidates. In Ekström, Mats, \& Patrona, Marianna (Eds.), Talking Politics in the Broadcast Media: Cross-Cultural Perspectives, 15-32. Amsterdam: John Benjamins.

Curl, Traci S., \& Drew, Paul. (2008). Contingency and action: A comparison of two forms of requesting. Research on Language and Social Interaction 41:1-25. 
Drew, Paul. (2003). Precision and exaggeration in interaction. American Sociological Review 68:917-938.

Drew, Paul. (2013). Turn design. In Sidnell \& Stivers, 131-149.

Durkheim, Émile. (2008[1912]). The elementary forms of religious life (Joseph Ward Swain, Trans.). Mineola, NY: Dover Publications.

Durkheim, Émile. (1951[1897]). Suicide: A study in sociology (J.A. Spaulding \& G. Simpson, Trans.). Glencoe, IL: The Free Press.

Elias, Norbert. (1992). An essay on time. Dublin: University College Dublin Press.

Enfield, N.J. (2013). Reference in conversation. In Sidnell \& Stivers, 433-454.

Enfield, N.J., \& Stivers, Tanya (Eds.). (2007). Person reference in interaction: Linguistic, cultural and social perspectives. Cambridge: Cambridge University Press.

Fillmore, Charles J. (1997). Lectures on deixis. Stanford: Center for the Study of Language and Information (CSLI) Publications.

Flaherty, Michael. (1999). A watched pot: How we experience time. New York: NYU Press.

Flaherty, Michael. (2011). The textures of time: Agency and temporal experience. Philadelphia: Temple University Press.

Flaherty, Michael, \& Fine, Gary Alan. (2001). Present, past, and future: Conjugating George Herbert Mead's perspective on time. Time \& Society 10:147-161.

Fox, Barbara A. (1987). Discourse structure and anaphora. Cambridge: Cambridge University Press.

Fox, Barbara A., \& Thompson, Sandra A. (2010). Responses to wh-questions in English conversation. Research on Language and Social Interaction 43:133-156.

Garfinkel, Harold. (1967). Studies in ethnomethodology. Englewood Cliffs: Prentice-Hall.

Geertz, Clifford. (1973). Person, time and conduct in Bali: The social nature of thought. The interpretation of cultures, 360-411. New York: Basic Books.

Gell, Alfred. (1992). The anthropology of time: Cultural constructions of temporal maps and images. Oxford: Berg.

Gibson, James J. (1979). The ecological approach to visual perception. Boston: Houghton Mifflin.

Giddens, Anthony. (1991). Modernity and self-identity: Self and society in the late modern age. Cambridge: Polity Press. 
Goffman, Erving. (1967). Interaction Ritual: Essays in Face to Face Behavior. Garden City: Doubleday.

Goffman, Erving. (1983a). Felicity's condition. American Journal of Sociology 89:1-53.

Goffman, Erving. (1983b). The interaction order. American Sociological Review 48:1-17.

Grice, H. Paul. (1957). Meaning. Philosophical Review 67:53-59.

Haakana, Markku. (2001). Laughter as a patient's resource: Dealing with delicate aspects of medical interaction. Text and Talk 21:187-219.

Heritage, John. (1984). Garfinkel and ethnomethodology. Cambridge: Polity Press.

Heritage, John. (2011). Territories of knowledge, territories of experience: Empathic moments in interaction. In Tanya Stivers, Lorenza Mondada \& Jakob Steensig (Eds.), The morality of knowledge in conversation, 159-183. Cambridge: Cambridge University Press.

Heritage, John. (2012). Epistemics in action: Action formation and territories of knowledge. Research on Language and Social Interaction 45:1-29.

Heritage, John. (2013). Epistemics in conversation. In Sidnell \& Stivers, 370-394.

Heritage, John, \& Raymond, Geoffrey. (2005). The terms of agreement: Indexing epistemic authority and subordination in assessment sequences. Social Psychology Quarterly 68:1538.

James, William. (1922). Principles of Psychology. New York: Macmillan and Co.

Jefferson, Gail. (1974). Error Correction as an Interactional Resource. Language in Society 2:191-199.

Jefferson, Gail. (1984). On the organization of laughter in talk about troubles. In Atkinson \& Heritage, 346-369.

Jefferson, Gail. (2004). Glossary of transcript symbols with an introduction. In G.H. Lerner (Ed.), Conversation analysis: Studies from the first generation, 13-31. Amsterdam: John Benjamins.

Kamio, A. (1997). Territory of Information. Amsterdam: John Benjamins.

Labov, W., \& Fanshel, D. (1977). Therapeutic Discourse: Psychotherapy as Conversation. New York: Academic Press.

Levinson, Stephen C. (2003). Space in language and cognition. Cambridge: Cambridge University Press. 
Luckmann, Thomas. (1991). The constitution of human life in time. In John Bender and David E. Wellbery (Eds.), Chronotypes: The construction of time, 151-166. Stanford: Stanford University Press.

Lyons, John. (1977). Semantics. Cambridge: Cambridge University Press.

MacWhinney, Brian. (2007). The TalkBank Project. In J.C. Beal, K.P. Corrigan, \& H.L. Moisl (Eds.), Creating and Digitizing Language Corpora: Synchronic Databases. Houndmills: Palgrave-Macmillan.

Mead, George Herbert. (1932). The philosophy of the present. Chicago: University of Chicago Press.

Mead, George Herbert. (1934). Mind, self, and society. Chicago: University of Chicago Press.

Mead, George Herbert. (1936). Movements of thought in the nineteenth century. Chicago: University of Chicago Press.

Mishler, E. (1984). The discourse of medicine: Dialectics of medical interviews. New Jersey: Ablex.

National Security Strategy of the U.S. (2006). On-line: http:/georgewbushwhitehouse.archives.gov/nsc/nss/2006/.

Parry R. H., Land, V., \& Seymour, J. (2014). How to communicate with patients about future illness progression and end of life: a systematic review. BMJ Supportive and Palliative Care 14:331-341.

Pomerantz, Anita M. (1984). Pursuing a response. In Atkinson \& Heritage, 152-164.

Postill, John. (2002). Clock and calendar time: A missing anthropological problem. Time and Society 11:251-270.

Raymond, Geoffrey, \& Heritage, John. (2006). The epistemics of social relations: Owning grandchildren. Language in Society 35:677-705.

Robinson, Jeffrey D. (2014). What 'what?' tells us about how conversationalists manage intersubjectivity. Research on Language and Social Interaction 47:109-129.

Roth, Julius. (1963). Timetables: Structuring the passage of time in hospital treatment and other careers. Indianapolis: Bobbs-Merrill Company.

Roy, William. (2001). Making Societies: The Historical Construction of the World We Live In. Boston: Pine Forge Press.

Sacks, Harvey. (1984). On Doing 'Being Ordinary'. In Atkinson \& Heritage, 413-429.

Sacks, Harvey. (1988/89). On members' measurement systems. Research on Language and Social Interaction 22:45-60. 
Sacks, Harvey. (1992). Lectures on conversation. Oxford: Blackwell.

Sacks, Harvey, \& Schegloff, Emanuel A. (2007[1979]). Two preferences in the organization of reference to persons and their interaction. In Enfield \& Stivers, 23-28.

Sacks, Harvey, Schegloff, Emanuel A., \& Jefferson, Gail. (1974). A simplest systematics for the organization of turn-taking for conversation. Language 50:696-735.

Schegloff, Emanuel A. (1972). Notes on a conversational practice: Formulating place. In David Sudnow (Ed.), Studies in social interaction, 75-119. New York: Free Press.

Schegloff, Emanuel A. (1987). Between Macro and Micro: Contexts and Other Connections. In Jeffrey C. Alexander, et al. (Eds.), The Micro-Macro Link, 207-234. Berkeley: University of California Press.

Schegloff, Emanuel A. (1996). Some practices for referring to persons in talk-in interaction: A partial sketch of a systematics. In Barbara Fox (Ed.), Studies in anaphora, 437-485. Amsterdam: John Benjamins.

Schegloff, Emanuel A., Jefferson, Gail, \& Sacks, Harvey. (1977). The preference for selfcorrection in the organization of repair in conversation. Language 53:361-382.

Schütz, Alfred. (1962). Commonsense and scientific interpretations of human action. In Maurice Natansin (Ed.), Alfred Schütz collected papers. The Hague: Martinus Nijhoff.

Searle, J.R. (1958). Proper Names. Mind 67:166-173.

Sidnell, Jack. (2013). Basic Conversation Analytic Methods. In Sidnell \& Stivers, 75-99.

Sidnell, Jack, and Tanya Stivers (Eds.) (2013). The handbook of conversation analysis. Malden, MA: Wiley-Blackwell.

Solomon, Olga. (2004). Narrative introductions: discourse competence of children with autistic spectrum disorders. Discourse Studies 6:253-76.

Sorokin, Pitirim. (1943). Sociocultural causality, space, time. Durham: Duke University Press.

Sorokin, Pitirim, \& Merton, Robert K. (1937). Social time: A methodological and functional analysis. American Journal of Sociology 42:615-629.

Stivers, Tanya. (2007). Alternative recognitionals in person reference. In Enfield \& Stivers, 7396.

Tillman, Katharine A., and David Barner. (2015). Learning the language of time: Children's acquisition of duration words. Cognitive Psychology 78: 57-77.

Tomasello, M. (2008). Origins of human communication. Cambridge: MIT Press. 
Turowetz, J. \& Maynard, D.W. (2016). Category attribution as a device for diagnosis: fitting children to the autism spectrum. Sociology of Health \& Illness 38:610-26.

Urry, John. (1985). Social relations, space and time. In D. Gregory \& J. Urry (Eds.), Social relations and spatial structures, 20-48. London: Macmillan.

Whorf, Benjamin. (2002[1940]). The relation of habitual thought and behaviour to language. In B.G. Blount (Ed.), Language, culture, and society, 64-84. Cambridge: Waveland Press.

Zerubavel, Eviatar. (1976). Timetables and scheduling: On the social organization of time. Sociological Inquiry 46:87-94.

Zerubavel, Eviatar. (1981). Hidden rhythms: Schedules and calendars in social life. Chicago: University of Chicago Press.

Zerubavel, Eviatar. (1982). The standardization of time: A sociohistorical perspective. American Journal of Sociology 88:1-23.

Zerubavel, Eviatar. (1985). The seven-day circle: The history and meaning of the week. New York: Free Press. 